\title{
Downhole distributed acoustic sensing reveals the wavefield structure of the coastal microseisms
}

\author{
Stanislav Glubokovskikh ${ }^{\mathrm{a}, *}$, Roman Pevzner ${ }^{\mathrm{a}}$, Evgeny Sidenko ${ }^{\mathrm{a}}$, Konstantin \\ Tertyshnikov $^{\mathrm{a}}$, Boris Gurevich ${ }^{\mathrm{a}}$, Sergey Shatalin ${ }^{\mathrm{b}}$, Alexey Slunyaev ${ }^{\mathrm{c}, \mathrm{d}}$, Efim \\ Pelinovsky ${ }^{\mathrm{c}, \mathrm{d}, \mathrm{e}}$ \\ ${ }^{a}$ Curtin University, GPO Box U1987, Perth 6845, Western Australia \\ ${ }^{b}$ Silixa Ltd, 230 Centennial Park, Centennial Avenue Elstree, Hertfordshire WD6 3SN, UK \\ ${ }^{c}$ National Research University-Higher School of Economics, 25 B. Pechorskaya Street, \\ Nizhny Novgorod 603950, Russia \\ ${ }^{d}$ Institute of Applied Physics, 46 Ulyanova Street, Nizhny Novgorod 603950, Russia \\ ${ }^{e}$ Nizhny Novgorod State Technical University, 24 Minina Street, N. Novgorod 603950, \\ Russia
}

\begin{abstract}
Ocean-generated seismic waves are omnipresent in passive seismic records around the world and present both a challenge for earthquakes observations and an input signal for interferometric methods for characterisation of the Earth's interior. Understanding of these waves requires the knowledge of the depthdependence of the oceanic noise at the transition into continent. To this end, we examine 80 days of continuous acquisition with Distributed Acoustic Sensor (DAS) system deployed in two deep boreholes near the south-eastern coast of Australia. The data has excellent Signal-to-Noise Ratio (SNR) in a range from $0.03 \mathrm{~Hz}$ to over $100 \mathrm{~Hz}$. By analysing the seismograms and correlation with wave climate, the DAS response are confidently decomposed into the microseisms generated by swell from remote storms $(\sim 0.15 \mathrm{~Hz})$ and local winds (between $0.3 \mathrm{~Hz}$ and $2 \mathrm{~Hz}$ ), and strong body waves energy from large surf break at the coast (from $2 \mathrm{~Hz}$ to $20 \mathrm{~Hz}$ ). The depth dependence of the microseims allows for robust normal modes analysis of the Rayleigh waves with only one borehole. The results of this analysis agree with the data from conventional dense seismological arrays. Overall, we found that the link between the amplitudes at each channel
\end{abstract}

\footnotetext{
*Corresponding author

Email address: stanislav.glubokovskikh@curtin.edu.au (Stanislav Glubokovskikh)
}

Preprint submitted to Earth and Planetary Science Letters

September 24, 2020 
along the borehole and wave climate is so strong and stable that with sufficient amount of training data, the passive seismic records on downhole DAS may be used for high-precision monitoring of both formations surrounding the borehole and remote storms in the ocean.

Keywords: oceanic microseisms, distributed acoustic sensing, passive seismic monitoring

\section{Introduction}

Motion of water in stormy seas induces omnipresent ambient seismic wavefield in the frequency band from $\sim 0.01 \mathrm{~Hz}$ to $\sim 20 \mathrm{~Hz}$ (Webb, 1998). These frequencies overlap with the frequency band of earthquake signals critical for seis-

5 mological observations by Ocean Bottom Stations (OBS), and hence has often been regarded as unwanted noise (e.g., Webb, 1998). Over the years, a link has been established between some components of the ocean-generated microseisms and wave climate in stormy seas (McCreery et al., 1993, Bromirski et al., 1999. Bromirski and Duennebier, 2002, Aucan et al., 2006), which allows the seismic 10 observations to be used for monitoring the sea conditions and the rock properties in the vicinity of the sensor. Furthermore, rapid development of interferometric methods expanded the research focus to the subsurface characterisation using passive seismic data (e.g., Nakata et al., 2019). However, inversion of the passive seismic observations often assumes stationary isotropic wavefield (Wape15 naar et al. 2010). This assumption is invalid for ocean-generated seismic energy, [which is highly directional and depends on the current sea conditions Bromirski and Duennebier, 2002, Gerstoft et al. 2006). A more accurate knowledge of the mechanisms responsible for generation of the seismic signals can significantly improve the accuracy of the estimated subsurface properties (e.g., Delaney 20 et al. 2017).

Global OBS networks provide the main means to study the seismic wavefield generated by the ocean (Webb, 1998; Stephen et al. 2003). These data sets feature two clear signals: primary, or Single Frequency (SF), microseisms at a 
peak frequency of the ocean waves and a much stronger Double Frequency (DF) microseisms at twice that frequency. The SF energy is related to the transfer of water surface oscillations into elastic energy through a direct interaction of the water waves with ocean floor (Hasselmann, 1963), and hence the intensity of these signals drops exponentially with the water depth. Typically SF microseisms become undetectable a few kilometeres into the continent Haubrich and

30 McCamy (1969); Bromirski and Duennebier (2002). In turn, DF microseims originate from nonlinear interaction of ocean wave trains of a similar frequency and opposite direction (Longuet-Higgins and Jeffreys, 1950; Hasselmann, 1963 , Kibblewhite and $\mathrm{Wu}, 1991$ ). The resulting oscillations penetrate almost lossless to the sea bottom and couple into leaky Rayleigh wave modes, which dominate

35 the low-frequency part of the seismic noise on land. Amplitudes of the seismic waves depend on the storm parameters in a large source region and the seismic properties of the ocean bottom (Webb, 1992, Tanimoto, 2007, Ardhuin et al. 2013 Gimbert and Tsai, 2015).

Overall, the mechanisms generating the seismic waves at the ocean bottom are relatively well understood, although a quantitative prediction of the microseisms remains a challenging problem. At the same time, transition of the microseisms into the continent is poorly understood. Conventional seismological arrays are too sparse for the ambient seismic wavefield $(\sim 10 \mathrm{~km})$. As a result, we only have coarse scale distribution of the velocities and intensity of

45 the propagating coherent signals from the kinematic and polarization analysis (Gerstoft et al. 2006, Brooks et al., 2009, Nakata et al. 2019). Moreover, depth-dependency of the seismic amplitudes is rarely available (Dorman and Prentiss, 1960), because seismic sensors are deployed either on the ground or in very shallow boreholes $(<100 \mathrm{~m})$ when the anthropogenic or other noise at the deployment site is high. Sometimes, ocean-related ambient noise is recorded in few points in a subsurface by microseismic arrays designed for fluid-induced seismicity in geological formations (e.g., Vaezi and van der Baan, 2014) or mines stability (Dolgikh et al. 2020). Without sufficent areal coverage and snapshots of the subsurface amplitude distribution, dynamics of rapidly changing ambi- 
ent seismic wavefield at the coast remains uncertain. Numerical simulations of this process are computationally expensive and are based on poorly constrained models of the subsurface and seismic source, and are able to capture only wellestablished features of the microseisms such as dependence on water depth or presence of the soft sediments at the bottom (Levchenko et al., 2011; Ying et al.

60 2014).

Distributed acoustic sensor (DAS) arrays based on fiber-optic technology offer a new way of multi-channel seismic acquisition in a broad frequency range capable of continuous recording of seismic wavefields and their spatial distribution. Recently, Lindsey et al. (2017); Yu et al. (2019) reported successful field tests of DAS measurements for seismological applications. DAS records have excellent Signal-to-Noise Ratio (SNR) for teleseismic earthquakes that have similar frequency content to the ocean noise. Lindsey et al. (2020); Williams et al. (2019) used communication optical fibre cables on shallow ocean bottom to characterize the microseism field. These measurements are however confined to the water-sediments transition boundary and hence provide only limited information about the propagation of the microseisms field deeper into the subsurface. More detailed information may be obtained from measurement of a DAS system in a sufficiently deep borehole. With the rapid development of the borehole seismic monitoring using DAS (e.g., Correa et al. 2017; Egorov et al., 2017), 75 the instrumented wells may be employed for ambient seismic monitoring.

This paper analyses ambient seismic wavefield in 80 days of continuous DAS acquisition by two boreholes with a depth of over 1500 m near the south-eastern coast of Australia. First, we describe the available data set and establish a link between traditional point sensors for displacement (seismometers and geophones) and DAS measurements. Second, we identify the physical nature of the seismic signals on DAS and their relationship with the wave climate using spectral characteristics and travel-time curves along the borehole. Then, analysis of the depth-dependence of the microseisms amplitudes along the borehole provides an estimate of the energy partition between the normal modes of the ${ }_{85}$ Rayleigh wave. In the end, we outline some unique capabilities and limitations 
of the DAS measurements in deep boreholes for monitoring both subsurface properties and wave climate.

\section{The data set}

Ambient seismic wavefield was recorded from 21 October 2018 to 07 Decemhave been drilled as a part of the CO2CRC Otway Project, Australian pilot research project focused on the geological sequestration of $\mathrm{CO}_{2}$ ( Cook, 2014). The Otway Project site is located at the shore of the Southern Ocean in the Australian State of Victoria, approximately 240km west of Melbourne (fig. 1a). with modern DAS systems. Seismic properties in the vicinity of the wells are available from sonic logs and numerous 3D borehole and surface seismic surveys with active sources (Glubokovskikh et al., 2016, Egorov et al., 2017, 2018).

Our analysis of the oceanic noise relies on remarkable performance of the modern DAS systems in a broad frequency range, especially at low frequencies (Lindsey et al. 2017). The seismic measurements by DAS estimate a rate of the axial deformation of the optical fibre $\epsilon_{z z}$ induced by a seismic wave. To this end, a DAS interrogator measures the phase difference between laser pulses packscattered from adjacent segments of the optical fibre. Appendix Appendix in iDASv ${ }^{T M}$ and iDASv2 ${ }^{T M}$ systems manufactured by Silixa (Elstree, Hertfordshire, UK, http://www.silixa.com), which are deployed in CRC-3 and CRC-2 wells, respectively. CRC-2 has a previous generation DAS system, which uses a standard single-mode optical communication fibre deployed on the production noise than the data from CRC-3, which has the cable cemented behind the casing (fig. 2). Note that the increased noise in the uppermost $\sim 270 \mathrm{~m}$ of both wells is due to surface casing, which causes intense mechanical reverberations of seismic signals. 
(a)

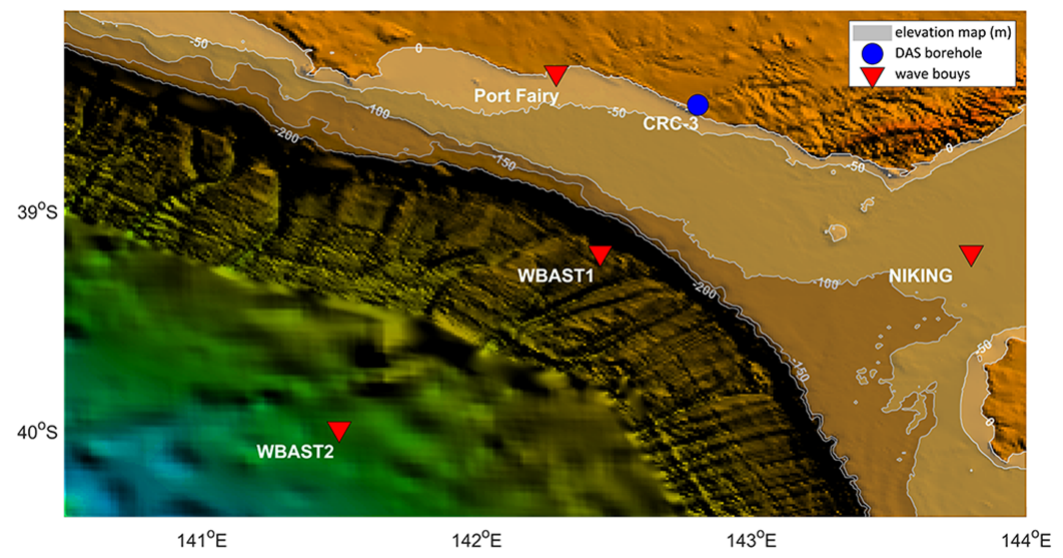

(b)

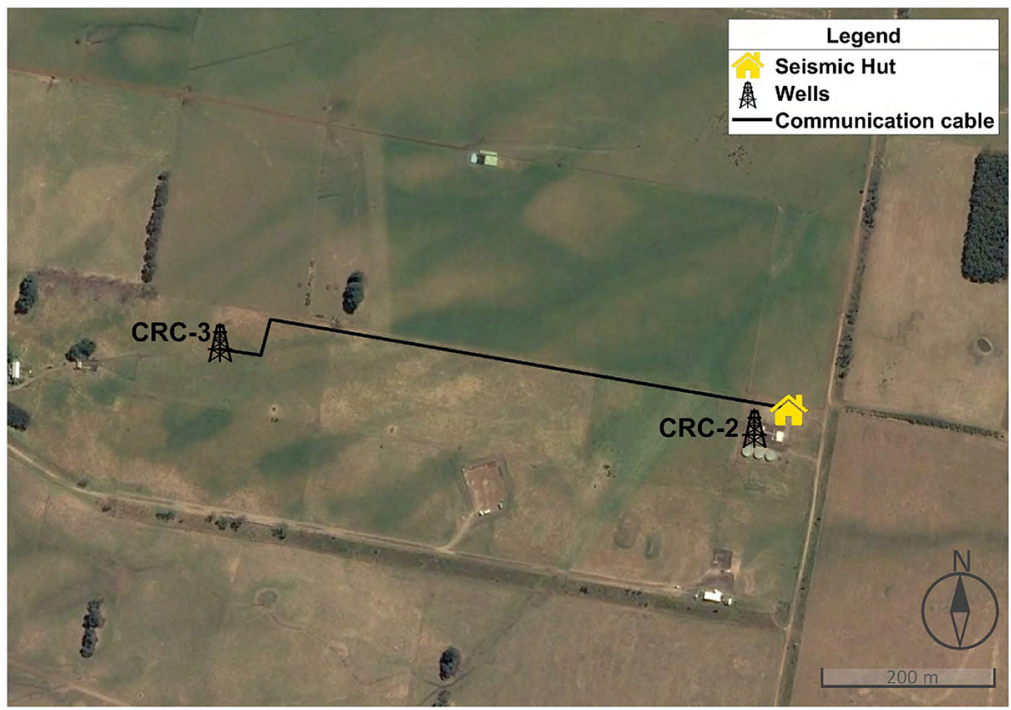

Figure 1: Outline of the experiment: elevation map (a) showing the positions of the monitoring well (blue circle) instrumented with distributed acoustic sensing system, CRC-3 well, and WAVEWATCHIII wave buoys (red triangles) of Victoria (Australia), and satellite image of the CO2CRC Otway Project site (b) with the position of the seismic recording system. 
In the following, we focus on the CRC-3 records. The seismic signal on DAS deployed in CRC-3 may be converted into the particle displacement along the fibre $u_{z}$ using factor $F_{D A S}\left(k_{z}\right)$ derived in appendix Appendix $\mathrm{A}$. The factor depends on the frequency $\omega$ of seismic signals and parameters of instrumentation: distance along the fibre between the reflection points of the backscattered pulse known as gauge length $L_{0}$, duration of the pulse $\tau$, and speed of light $c$ in the fibre material. For small $k_{z}$, a projection of the seismic wave vector on the fibre, equation A.10 for the DAS response reduces to

$$
F_{D A S}\left(k_{z}\right)=-\frac{L_{0} \tau c}{4}\left(\omega \cdot k_{z}\right) .
$$

Equation (1) shows that for most types of seismic waves, the DAS sensitivity drops with decreasing frequency relatively quickly, as $\omega^{2}$. However, the phase interferometry approach implemented in iDASv $3^{\mathrm{TM}}$ provides sufficient SNR starting from a few millihertz. Pevzner et al. (2020a) showed that eq. (1) holds true for the DAS system in CRC-3 and the data still provides clear records of teleseismic earthquakes. In the following sections we divide the spectral amplitude of the DAS response by $\omega$, to make DAS data more consistent with the conventional seismological records, which measure either particle displacement or its temporal derivatives, velocity and acceleration.

\section{DAS response versus wave climate}

The DAS record in CRC-3 (fig. 2a) shows an abundance of ambient seismic energy at all depth levels. The Otway site is located in the area of active farming; previous analysis (Pevzner et al., 2020b) showed DAS records containing distinct anthropogenic noise: monochromatic signals from various farming machinery, impulse sources, and even routine movement of cattle. Yet, the records are dominated by low-frequency surface waves with an apparent period $\sim 2 \mathrm{~s}$ propagating horizontally and frequently repeated body waves and their scattered modes with an average period below 0.5 s propagating at an angle to the borehole receiver array. In the following we show that these signals are generated by the ocean. 
(a)

(b)
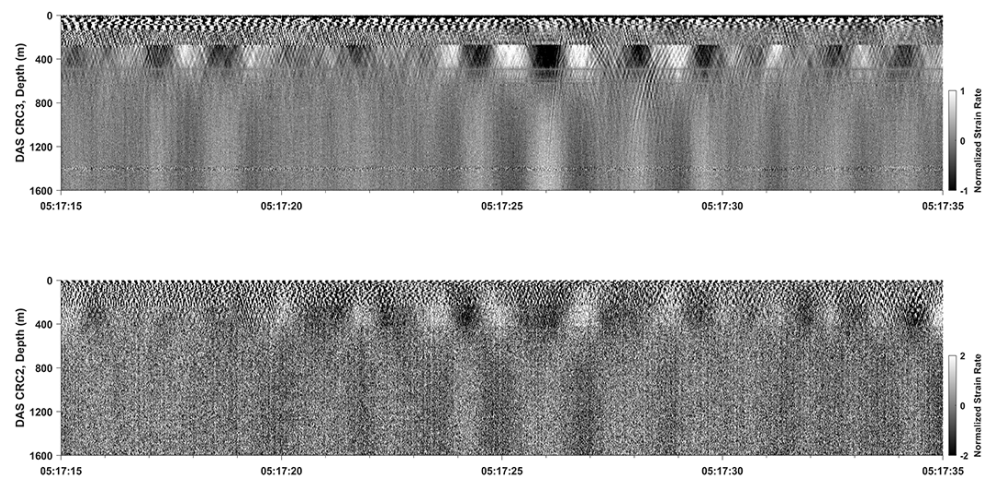

Figure 2: A fragment of raw seismic data records in the CRC-3 well (a) and CRC-2 well (b). The record starts at 05:17:15 UTC on the $15^{\text {th }}$ of November 2018. Vertical scale corresponds to the measured depth along the boreholes, as both wells are nearly vertical. The stronger noise in the top $270 \mathrm{~m}$ in both wells is due to the surface casing.

Figure 3 compares the low-frequency seismic response in CRC-3 with the pceanic wave climate (WAVEWATCH III monitoring system https://polar. ncep.noaa.gov/waves/hindcasts/nopp-phase2.php). Since records on all of the nearby buoys are very similar, in the following we only show data from WBAST1 buoy. Qualitatively, we see that storms - distinguished by high wind speed $W_{S}$ and significant wave height $H_{S}$ - correspond to high intensity of the DAS response in the range from 0.1 to $2 \mathrm{~Hz}$. The peak magnitude persistently occurs at $\sim 0.6 \mathrm{~Hz}$. According to the frequency dependence of the correlation coefficients (fig. 4a), we divide the DAS records into several groups:

1. <50mHz: no ocean-related energy detectable;

2. from $50 \mathrm{mHz}$ to $120 \mathrm{mHz}$ : gradual increase of the ocean-related microseisms;

3. 150mHz: classical DF microseisms;

4. $\sim 0.3 \mathrm{~Hz}$ to $2 \mathrm{~Hz}$ : local microseisms;

5. from $2 \mathrm{~Hz}$ to $20 \mathrm{~Hz}$ : frequently recurring body waves;

6. $>20 \mathrm{~Hz}$ : vibrations of the recording unit caused by local wind.

In group 1. microseisms, if any, are weaker than the instrumental noise. 


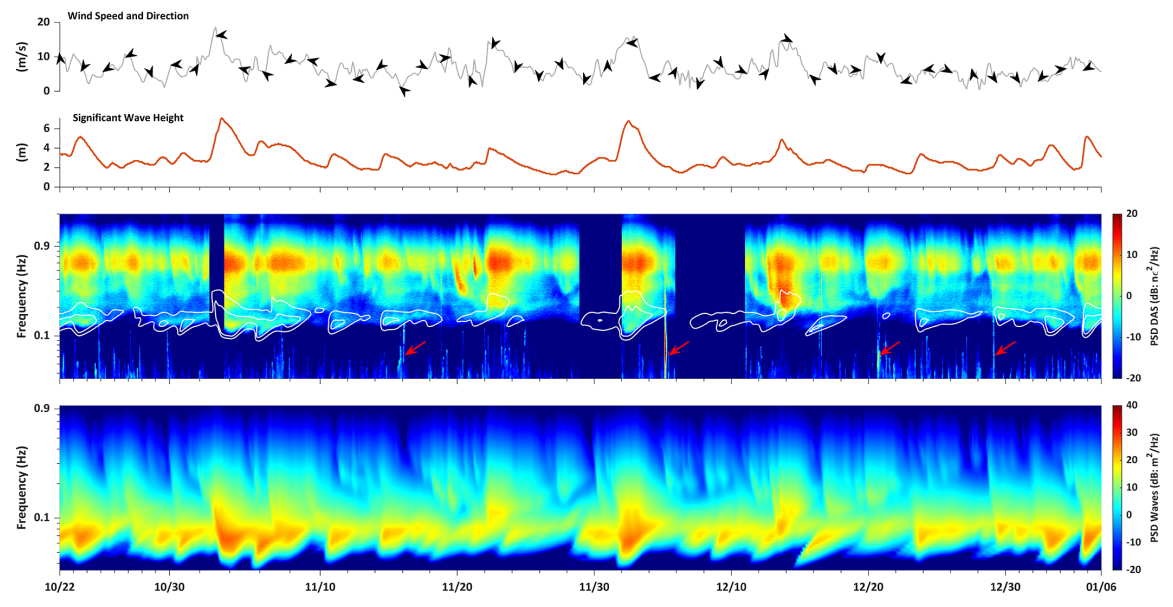

Figure 3: Comparison of the low frequency response on distributed acoustic sensing data in CRC-3 against the wave climate recorded by buoy WBAST1 (see fig. 1a): the ocean wave spectrogram (Welch (1967) average for 3a -hour segment with 30 min window) (bottom panel); spectrogram of the seismic response divided by angular frequency $\omega$ (Welch (1967) average for a 2-hour segment with 5 min window an $50 \%$ overlap), where the white lines correspond to the $10 \mathrm{db}$ and $15 \mathrm{db}$ contours of the ocean wave spectrum plotted in doubled frequency scale (middle panel); significant wave height and wind speed and direction (top panel). The red arrows indicate arrivals of strong teleseismic earthquakes. 
(a)

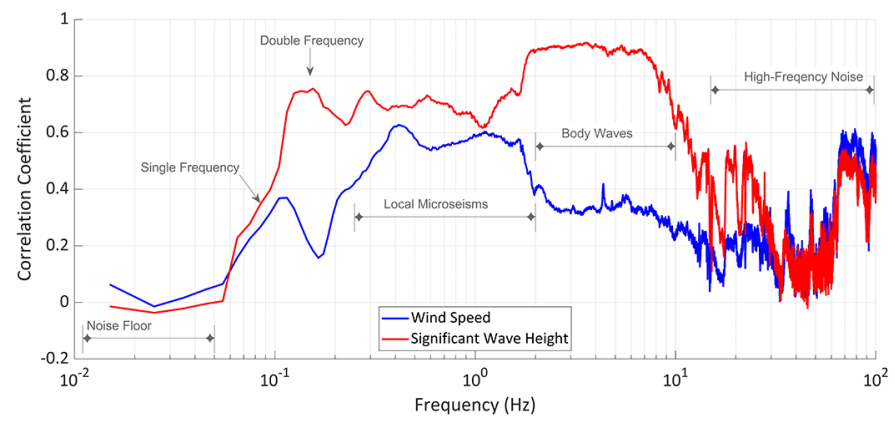

(b)

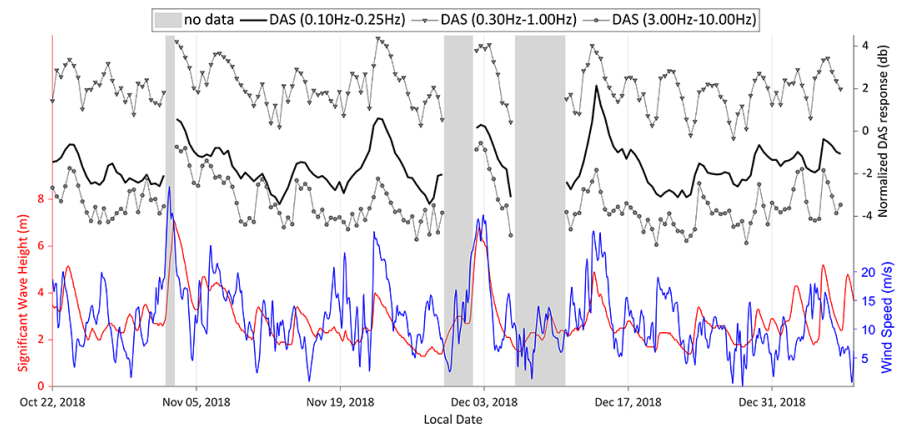

Figure 4: Relationship between the strength of the seismic response at a depth of $300 \mathrm{~m}$ in the CRC-3 well and wave climate at the coast: correlation coefficient of the wind speed and significant wave height with the power spectrum density ( $\mathrm{dB}$ scale) of seismic signals computed with the $0.01 \mathrm{~Hz}$ spacing (a); temporal variation of the wind speed, significant wave height and intensity of the classical double frequency microseisms, local microseisms and body waves excited by surf break normalized to their standard deviation. 
Between $50 \mathrm{mHz}$ and $120 \mathrm{mHz}$, although the correlation coefficients gradually increase, the intensity of the primary microseisms at $\sim 70 \mathrm{mHz}$ is relatively low and a peak at $<0.1 \mathrm{~Hz}$ only seldom appears in the data. Group 6 contains highfrequency clutter, which is unlikely to come from the ocean. Indeed, seismic $Q$ in the area is about 100 or smaller (Pirogova et al. 2019), and hence these waves would attenuate substantially at distances on the order of several kilometers. Instead, signals at frequencies over $20 \mathrm{~Hz}$ may be caused by wind-induced mechanical vibrations of the hut housing the recording unit. We omit a further discussion of groups 1, 2 and 6, because they are affected by characteristics of the acquisition system, rather than the ambient seismic field. In the remaining frequency range, $0.1 \mathrm{~Hz}-20 \mathrm{~Hz}$, the DAS data stably provides high SNR as evident from high correlation with features of the wave climate.

The correlation peak for $H_{S}$ at $\sim 150 \mathrm{mHz}$ corresponds to twice the peak ocean wave frequency and hence represents the classical DF microseisms. These seismic signals are studied extensively in the literature and our data agree with numerous reports from around the world (e.g., Webb, 2007; Bromirski and Duennebier, 2002, Nakata et al., 2019): the contours of the buoy spectrum plotted versus double frequency capture the structure of the DAS spectrum up to $0.2 \mathrm{~Hz}$ (see fig. 3). Interestingly, correlation with $W_{S}$ drops noticeably at this frequency, which merely indicates significant contribution of the swell arriving from remote storms into the local wave climate. These microseims arrive at CRC-3 well as a plane surface wave with relatively high magnitude at all depths and polarity reversal at $\sim 700 \mathrm{~m}$ (see fig. 5a).

Unlike the DF microseims, strong energy in group 4 is uncommon for the passive seismic records. For the range between $\sim 0.3 \mathrm{~Hz}$ and $2 \mathrm{~Hz}$, the correlation is high for both $H_{S}$ and $W_{S}$, which suggests that the microseisms are generated by local wind waves. A similar correlation of the microseisms with local wind has been reported for ocean bottom stations in the east Pacific ocean, and seismometers in Iceland (Bromirski et al., 1999) and Hawaii (McCreery et al., 1993 Garcés et al. 2006). Ocean waves depend on the strength, duration and 190 size of the storm (Pierson Jr. and Moskowitz, 1964). Strong low frequency 
( $\sim 15$ s period) waves require stably strong winds over an extended area, while formation of high frequency ocean waves occurs relatively quickly: around 5 hours for $4 \mathrm{~s}$ period. During the data acquisition, minimum wind speed was $4 \mathrm{~m} / \mathrm{s}$ and the average speed $8 \mathrm{~m} / \mathrm{s}$, which should be sufficient to 'saturate' the part of the wave spectrum corresponding to periods from 1s to $6 \mathrm{~s}$ (Pierson Jr. and Moskowitz, 1964). The local microseisms travel as a surface wave with depth dependence of amplitudes very similar to the DF microseisms (fig. 5b).

Group 5 has frequencies that cannot be directly related to the frequency of ocean waves. Yet they show strong correlation of the seismic amplitudes to the amplitudes of ocean waves, but not with the wind speed. Garcés et al. (2006); Aucan et al. (2006); McCreery et al. (1993) reported similar observations on coastal stations and some evidence that the seismic energy in the range between $2 \mathrm{~Hz}$ and $20 \mathrm{~Hz}$ is caused by abrupt impacts of breaking surf at the coast. Our data agree with this hypothesis. The filtered seismograms contain clearly visible recurring body wave arrivals (fig. 5c), with travel-time curves indicating waves propagating at an angle to the surface. Indeed, reverberations of shear waves are ubiquitous in the soft carbonate sediments in the upper $600 \mathrm{~m}$. Furthermore, pairs of compressional and shear waves arrive from beneath CRC3 with almost constant time delay. A detection algorithm based on matching the compressional and shear travel-time curves has identified about 60,000 such events over 70 days of recording, The behaviour of correlation coefficients in this frequency band indicates that the abundance and strength of these events is controlled by the significant wave height.

A peculiar feature of the DAS records in CRC-3 is a steadily high strength of the microseisms at $0.6 \mathrm{~Hz}$, while traditionally seismic records are dominated by signals with frequency equal to twice the peak frequency of ocean waves (Webb, 1998, Nakata et al., 2019). Commonly accepted models (e.g., Pierson Jr. and Moskowitz, 1964) predict that with increasing wind speed, the short-period ocean waves reach maximum intensity quickly, while progressively 220 lower-frequency waves become stronger with increasing wind speed. Therefore, the wave height energy and hence microseisms spectrum decrease rapidly with 
increasing frequency. It is believed that above $0.3 \mathrm{~Hz}$, microseisms have a worldwide constant Holu spectrum (McCreery et al., 1993, Bromirski et al., 1999). But the nonlinear generation of the microseisms requires interaction of ocean waves of a similar frequency and opposite direction. Hence the strength of DF microseisms at each frequency, expressed as the power spectral density of the vertical displacement $I(\omega)$, depends on the distribution of the intensity of ocean waves $A(\omega / 2, \theta)$ over azimuth $\theta$. With a few reasonable assumptions, the relationship has the following simple form (see equation (7) in Webb, 1992)

$$
I(\omega) \propto \omega \cdot \int_{0}^{\pi} A(\omega / 2, \theta) A(\omega / 2, \theta+\pi) d \theta .
$$

The buoy data in the area shows the tendency of the high-frequency ocean waves to form pairs of sufficiently strong opposing wavetrains (see fig. 6). Predicted frequency spectra of the microseisms are in good agreement with the theoretical predictions of eq. (2). This suggests that the peak frequency in the DAS response may be a consequence of the peculiar wave climate at the Victorian coast. The frequency shift may be further increased due to factor $k_{Z}$ in the DAS response (see eq. (1)), which increases with frequency.

\section{Variation of strain with depth in the microseisms}

Spectrogram in fig. 7a shows a typical intensity distribution of the DAS measurements along the CRC-3 borehole: first, amplitudes decrease towards a pronounced minimum at $\sim 700 \mathrm{~m}$ depth; then the amplitudes increase steadily towards the bottom of the well. The minimum corresponds to the polarity reversal as seen in fig. $5 \mathrm{a}$ and fig. $5 \mathrm{~b}$ for $\mathrm{CRC}-3$ and in the raw data for CRC-2 well (fig. 2). Since CRC-2 and CRC-3 have different well designs and different DAS recording systems, the common features of the seismic record indicate that the seismograms bear only small overprint of the acquisition system and accurately represent the wavefield structure of the microseisms.

A commonly accepted hypothesis is that ocean-induced microseisms travel predominantly as Rayleigh waves, with the energy partition between the normal 
(a)

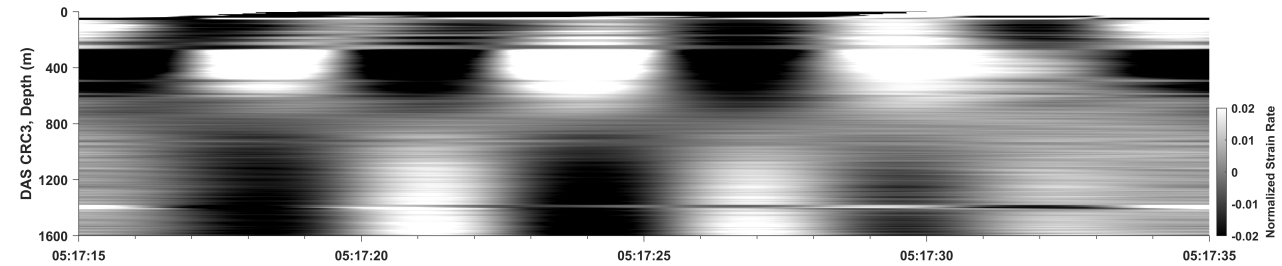

(b)

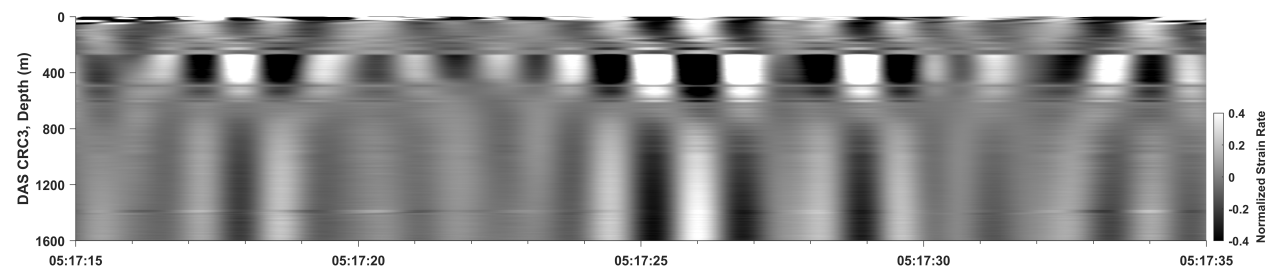

(c)

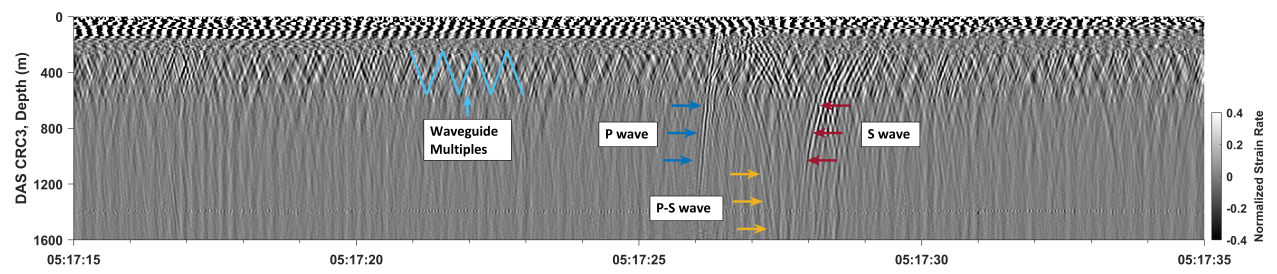

Figure 5: A typical example of the ocean-generated noise in the seismic records in the CRC-3 well. The raw seismogram from fig. $2 \mathrm{a}$ is filtered (Ormsby filter) in three frequency bands: $0.1 \mathrm{~Hz}-0.2 \mathrm{~Hz}$ (a) corresponds to the double frequency response to the peak in the ocean wave spectrum; $0.3 \mathrm{~Hz}-2 \mathrm{~Hz}$ (b) corresponds to local microseisms; $2 \mathrm{~Hz}-20 \mathrm{~Hz}$ (c) corresponds to the energy induced by surf breaks, where arrows indicate the travel-time curves for different components of the wavefield. The stronger noise in the top $270 \mathrm{~m}$ in both wells is due to the surface casing. 
(a)
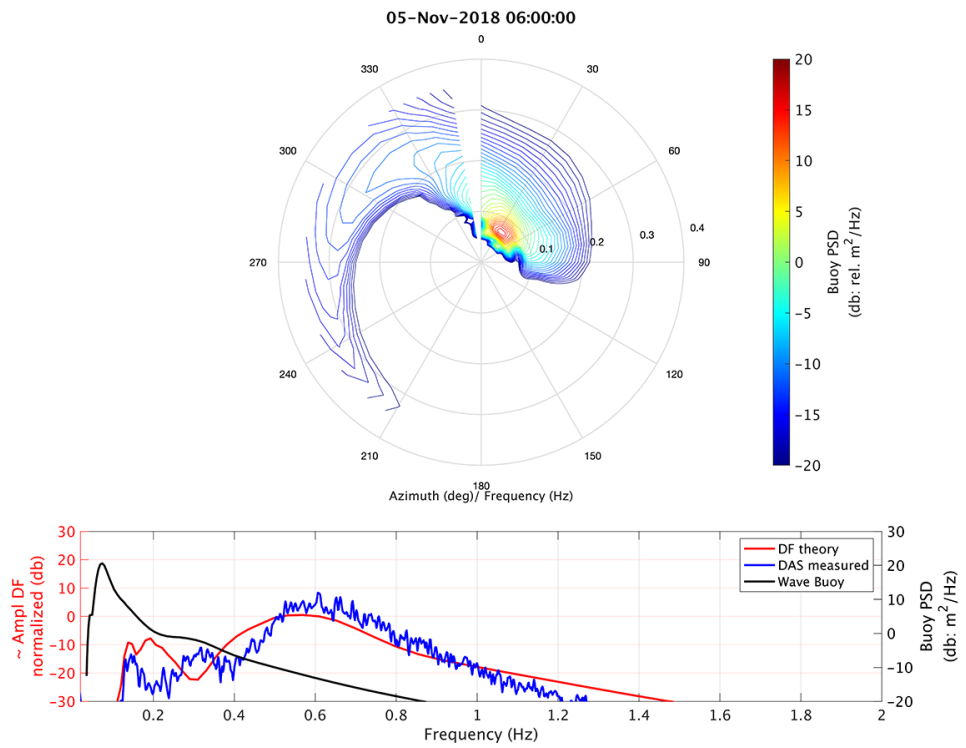

(b)
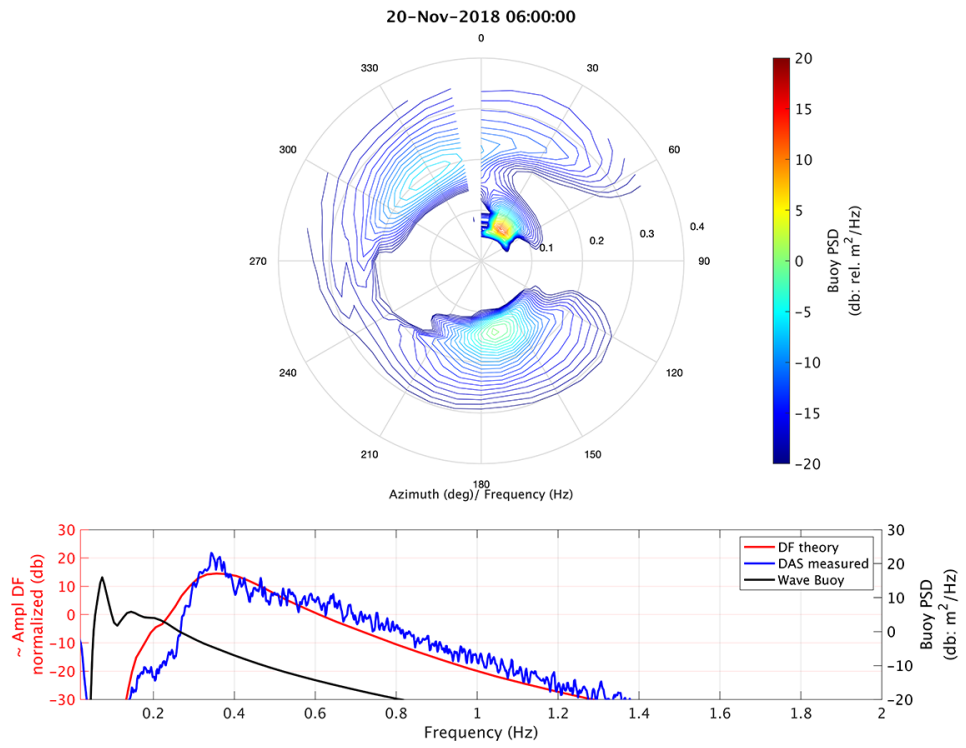

Figure 6: Comparison of the observed microseisms with theoretical prediction in CRC-3 at $300 \mathrm{~m}$ true vertical depth. The top row shows typical examples of directional ocean wave spectra. At the bottom, power spectral density in the DAS data is plotted against the theoretically predicted $I(\omega)$ using eq. 22, which is normalized to the measured DAS response at $0.6 \mathrm{~Hz}$ to facilitate the comparison. The directional spel5ra correspond to WBAST1 buoy (see fig. $1 \mathrm{a}$. 
(a)

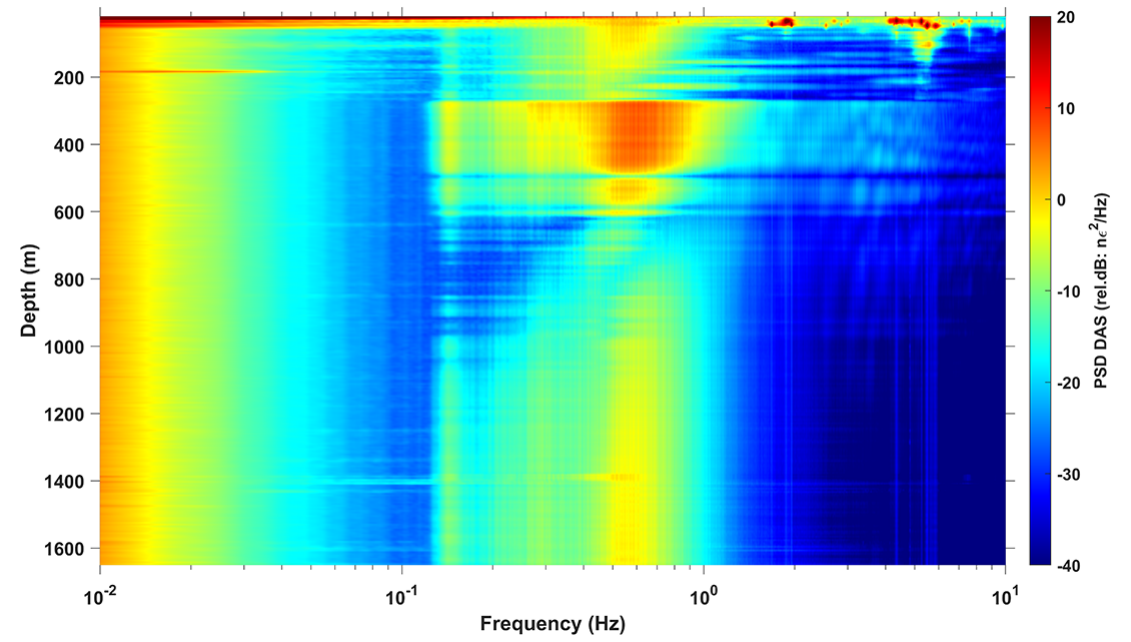

(b)
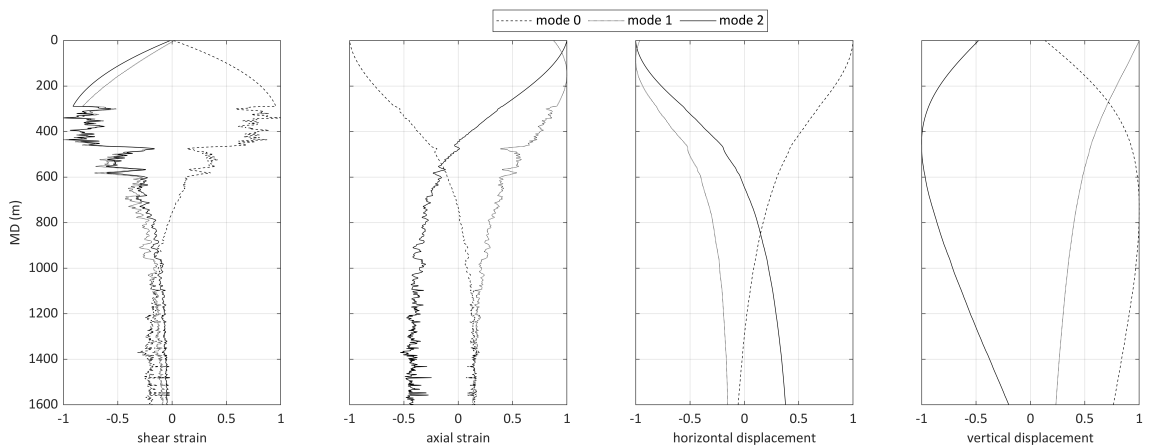

(c)
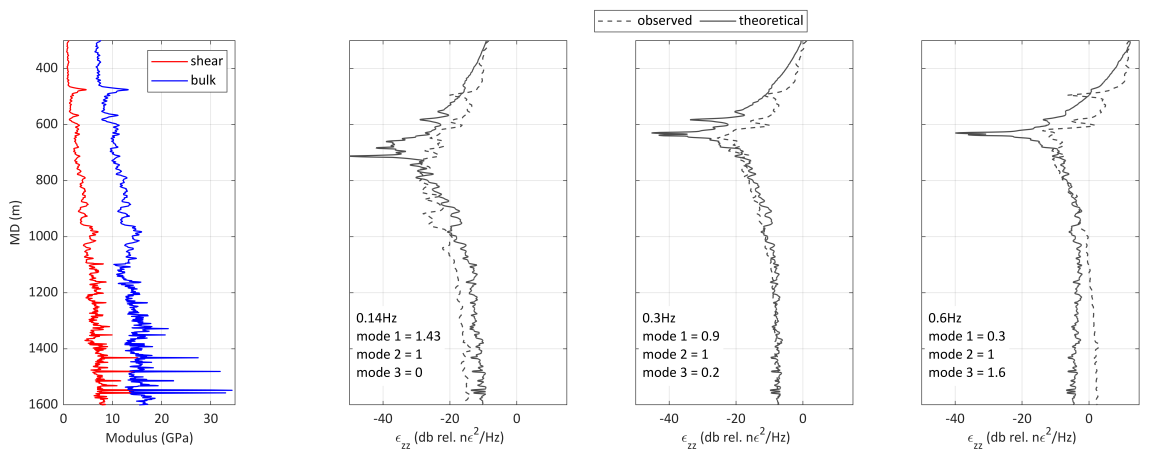

Figure 7: Variation of the intensity of the seismic response in distributed acoustic sensing measurements in CRC-3 well. Spectrogram (a) is computed using Welch (1967) approach within 4 hours and 10 minute window, the segment starts at 04:00:00 on the $15^{\text {th }}$ of November 2018. Normal modes for frequency of $0.6 \mathrm{~Hz}$ (b) are computed using the velocity model for the CRC-3 well (c). The rest of the panel (c) 16 compares the observed vertical distribution of the power spectral density of the seismic measurements and a best-fit linear combination of the normal modes (the coefficients are normalised to the magnitude of the first mode). Note that the spectra are compensated for the effect of frequency. The noise in the top $270 \mathrm{~m}$ in both wells is due to the surface casing. 
modes controlled by the parameters of the source region: frequency of the ocean studies reported significantly lower intensity of the microseisms at frequency $>0.3 \mathrm{~Hz}$, while in our data, the peak occurs at $\sim 0.6 \mathrm{~Hz}$.

Another feature of the measured DAS intensity is a clear dependence on the 

2017). At the same time, DAS may be seen as a valuable addition to arrays of existing seismological monitoring systems, as it provides the only means for 
imaging of the subsurface wavefield.

Besides the parameters of the ocean surface, transition of the microseisms energy into the continent depends on the bathymetry, elastic properties of the rocks at and beneath the bottom, their attenuation and geological section onshore. We think that the latter two factors may play an important role in our observations. The wavefield in the upper $600 \mathrm{~m}$ of the record is clearly different from the lower part: a decreased stiffness of the sediments along with a strong reflector at $600 \mathrm{~m}$ may serve as a waveguide for the low frequency signals. A set of numerical simulations may help evaluate the importance of the local geological structure. But again, the simulation would require a realistic source function, because modelling with simple impulsive sources may provide only coarse structure of the wavefield (Levchenko et al., 2011; Ying et al., 2014), which lacks sufficient detail for our purposes. Another unknown for accurate modelling of the microseisms is seismic attenuation in the sediments at sub- $\mathrm{Hz}$ frequencies, which can alter the frequency content of the microseisms as they propagate inland.

The first step towards an adequate source function is the location of the source region, which is impossible with a single well. The Otway Project site has five wells instrumented with iDASv3 ${ }^{\top M}$ systems (Pevzner et al., 2020c), within a distance of $2 \mathrm{~km}$. Even such a small aperture may be sufficient to accurately delineate the source regions, and hence, establish a link between the ocean parameters and seismic signal, similar to Bromirski et al. (1999); Bromirski and Duennebier (2002). For a multi-well DAS array, we will have a separate link for each channel (depth) and each well. Also, since the fine-scale variation of the strain measurements by DAS is directly related to the stiffness of the surrounding rocks, passive seismic records may become a means for repeat elastic logging of the formation changes. With ever-growing recognition of the value of downhole DAS systems, this technology may become an important subsurface surveillance tool. 


\section{Conclusions}

This study demonstrated a substantial potential of passive seismic records

340 ocean-generated seismic signals. The data acquired at the CO2CRC Otway Project site has high signal-to-noise ratio for frequencies from $10 \mathrm{mHz}$ to $100 \mathrm{~Hz}$. Below $20 \mathrm{~Hz}$, the intensity of the seismic response has a clear correlation with the wave climate in the nearby ocean. Frequencies above $20 \mathrm{~Hz}$ correspond to frequencies and for variety of the source regions in the ocean: the surface waves change polarity at the same depth where rock stiffness changes dramatically. Such stability suggests a strong dependence of microseisms structure on the geological section in the immediate vicinity of the borehole. Normal modes analysis contribution from higher Rayleigh modes even at low frequencies $(\sim 100 \mathrm{mHz})$.

A more comprehensive analysis of the ocean-generated seismic signals re- 
quires a better control of the source contribution into the response on distributed acoustic sensing data. However, the link between the amplitudes at each channel along the borehole and wave climate appears so strong and stable that with sufficient amount of training data, the passive seismic records may be used for high-precision monitoring of both formations surrounding the borehole and remote storms in the ocean.

\section{Acknowledgements}

The Otway Project received CO2CRC funding through its industry members and research partners, the Australian Government under the CCS Flagships Programme, the Victorian State Government and the Global CCS Institute. The authors wish to acknowledge financial assistance provided through Australian National Low Emissions Coal Research and Development (ANLEC R\&D). ANLEC R\&D is supported by COAL21 Ltd and the Australian Government through the Clean Energy Initiative. The authors are grateful to Silixa ltd for providing the DAS interrogators for this experiment and other technical support. We are also grateful to Ludovic Ricard (CSIRO), Michael Mandanos (Silixa), Paul Barraclough (CO2CRC Ltd) and Peter Dumesny (Upstream Production Solutions) for their help with the field experiment and Sofya Popik and Andrej Bona (both Curtin University) for their help with the manuscript preparation. Efim Pelinovsky acknowledges the support from the RFBR grant No 19-55-15005.

\section{Appendix A. DAS measurements of the seismic signals}

This section aims to introduce the Distributed Acoustic Sensing (DAS) measurements to a broader audience. A rigorous derivation of the DAS response to the fibre vibration involves a relatively sophisticated apparatus of statistical optics (e.g., Goodman, 2015). However, essential elements of the DAS technology may be explained by a simple 1D convolutional model for the intensity of

laser pulses backscattered from the fibre, which underlies the interpretation of 
Optical Time Domain Reflectometry (OTDR). We anlyse the optical field $E\left(t^{\prime}\right)$ emerging at the beginning of the fibre due to the backscattering of a pulse $s\left(t^{\prime}\right)$, where $t^{\prime}$ is a two-way travel-time. This travel-time is related to the distance to a reflection point $z=c t^{\prime} / 2$, where $c$ is a speed of light in the fibre (typically, $1 \mathrm{~m}$ corresponds to 10ns). With some reasonable assumptions, the backscattered field may be modelled as a linear function of the fibre reflectivity $r(z)$

$$
E\left(t^{\prime}\right)=s\left(t^{\prime}\right) * r\left(c t^{\prime} / 2\right),
$$

where $*$ denotes the convolution operator. We assume an idealised laser source that generates a monochromatic pulse of temporal frequency $\omega$ and width $\tau$. Note, eq. A.1 is true for a clean fibre, where transmitted pulses undergo negligible distortion of the phase and amplitude, and multiple scattering effects are negligible.

In the presence of time-dependent displacements $u(z, t)$, the reflectivity becomes a function of $v(z, t)=\frac{\partial u(z, t)}{\partial t}$, a relative particle displacement velocity at different parts of optical fiber at a moment in time $t$. To retrieve $v(z, t)$ induced by a seismic wave, DAS systems must accurately measure the temporal variation of the OTDR intensity $I\left(t^{\prime}\right)=E^{2}\left(t^{\prime}\right)$. The main challenge for a practical implementation of the OTDR-like approach is generation of stable laser pulses, otherwise temporal fluctuations of $s(t)$ would obscure any signal due to $v(z, t)$. In communication networks, OTDR uses incoherent pulses, and its output is insensitive to variations of the optical phase along fiber. But even with the best existing laser sources, the coherent OTDR can provide only qualitative estimates of the particle velocity $v(?)$.

In all the quantitative DAS approaches, the effect of fibre movement on the reflected optical field is estimated using interferometric techniques (Hartog, 420 2017). The main idea is to compare pulses reflected at adjacent points on the fibre. Interference of these pulses is controlled by the reflection coefficients and their relative movement, but a specific form of the DAS response depends on the instrumentation configuration. Figure A.8 illustrates an implementation of this approach using an interferometer with a delay line of length $2 L_{0}$. In the 

the delayed pulse interferes with a pulse that was reflected from a point offset by $L_{0}$ and then passed through the straight line. Thus, $L_{0}$ is often called a gauge length, a key parameter that controls the spatial resolution of the DAS measurements.

430 $v(z, t)=v_{0} \cdot \delta\left(z-z_{0}\right)$ at a single point $z_{0}$ along the fibre $(\delta(\cdot)$ denotes a Dirac delta function). This approach represents the well-known dualism, when a change in interference can be considered either as a result of a phase change or as a frequency beats due to a Doppler shift (?). The pulse $s_{2}$ reflected from $z_{0}$ has frequency $\Omega= \pm v_{0} \omega / c$, where the positive sign corresponds to contraction of the fibre and negative to the extension. First, $s_{2}$ interferes with a pulse $s_{1}$ coming out of the delay line, then, $s_{2}$ that passed through the delay line interferes with $s_{3}$ coming out of the straight line. For the first interference, the intensity observed in a photodetector, $I_{12}$, may be expressed as

$$
I_{12}\left(t^{\prime}\right)=\left(r_{1}^{2}+r_{2}^{2}+2 r_{1} r_{2} \cos \left(\Omega t^{\prime}\right)\right) \cdot s^{2}\left(t^{\prime}-2 z_{0} / c\right)
$$

A similar expression describes the second interference $I_{23}$. Equation A.2 shows that the absolute value $\left|v_{0}\right|$ defines the beat frequency of the photon counts. For example, the magnitude of the oscillations $I_{\Omega}$ of $\frac{\partial I_{12}(t)}{\partial t}$ may be expressed as

$$
I_{\Omega}(z) \propto s^{2}\left(z-z_{0}\right) \rho^{2}\left(z_{0}\right) \cdot v_{0},
$$

445 new parameter $\rho(z) \sim \sqrt{r(z) r\left(z-L_{0}\right)}$, which approximates $r(z)$ if the reflectivity varies slowly.

The proposed simple implementation of the DAS measurement in fig. A.8 is useful for understanding the principle, but it may provide only the absolute value of the displacement velocity along the fibre. The retrieval of the sign of $v$ requires a more complicated system; conceptually it replaces the simple 
differentiator after the photodetector in fig. A.8 with a so called 'strain analyser', which performs a more involved transformation of the interfering signals.

The effect of a distributed displacement velocity field $v(z)$ on the DAS response, $A(z)$ may be represented as a superposition of the point reflections with a Doppler shift towards each other $\Delta \Omega(z)=\omega / c \cdot\left[v(z)-v\left(z-L_{0}\right)\right]$. Hence, we may think of $I_{\Omega}$ as a point spread function of the DAS measurements, although the measurements involve a few nonlinear transformations. So the resultant equation for the DAS response is

$$
A(z)=I_{\Omega}(z) * v(z)=s_{0}^{2}(z) * \rho^{2}(z) *\left[v(z)-v\left(z-L_{0}\right)\right] .
$$

For slow variation of the displacement velocity field along the fibre $\left(\gg L_{0}\right)$, eq. A.4 shows that DAS response is proportional to an axial strain rate of the fibre $\epsilon_{z z}=\frac{\partial v(z, t)}{\partial z}$.

Equation A.4 shows that the effect of the fibre deformation bears an overprint of the spatial variations of the reflectivity along the fibre. The approach to removal of the effect of $r(z)$ constitutes the main difference between iDASv $3^{\mathrm{TM}}$ and iDASv2 ${ }^{T M}$ systems. The reflectivity in a conventional single-mode fibre is associated with Rayleigh scattering on low-contrast fluctuations of the optical refraction index, an inherently random process. Strictly speaking, elimination of this random effect would require an ensemble of the DAS measurements for the same velocity field $v(z, t)$ but different fibres followed by analysis of the ensemble average $\langle A(z)\rangle$. For Rayleigh scattering, eq. A.4 simplifies to

$$
\left\langle A_{\mathrm{DAS}}(z)\right\rangle=s_{0}^{2}(z) *\left[v(z)-v\left(z-L_{0}\right)\right],
$$

To illustrate the effect of random fibre reflectivity, ? simulated numerically the DAS response corresponding to the movement of a $40 \mathrm{~m}$ segment of fibre (no deformation occurs inside the segment), for $\tau=10-100 \mathrm{~ns}$ and the gauge 475 length $L_{0}=10 \mathrm{~m}$ (fig. A.9). If the pulse width is small, agreement with the theory is good. But for a typical pulse width, this effect causes significant errors in estimates of the velocity field $v(z)$.

This observation explains a general approach to choosing the pulse width. 


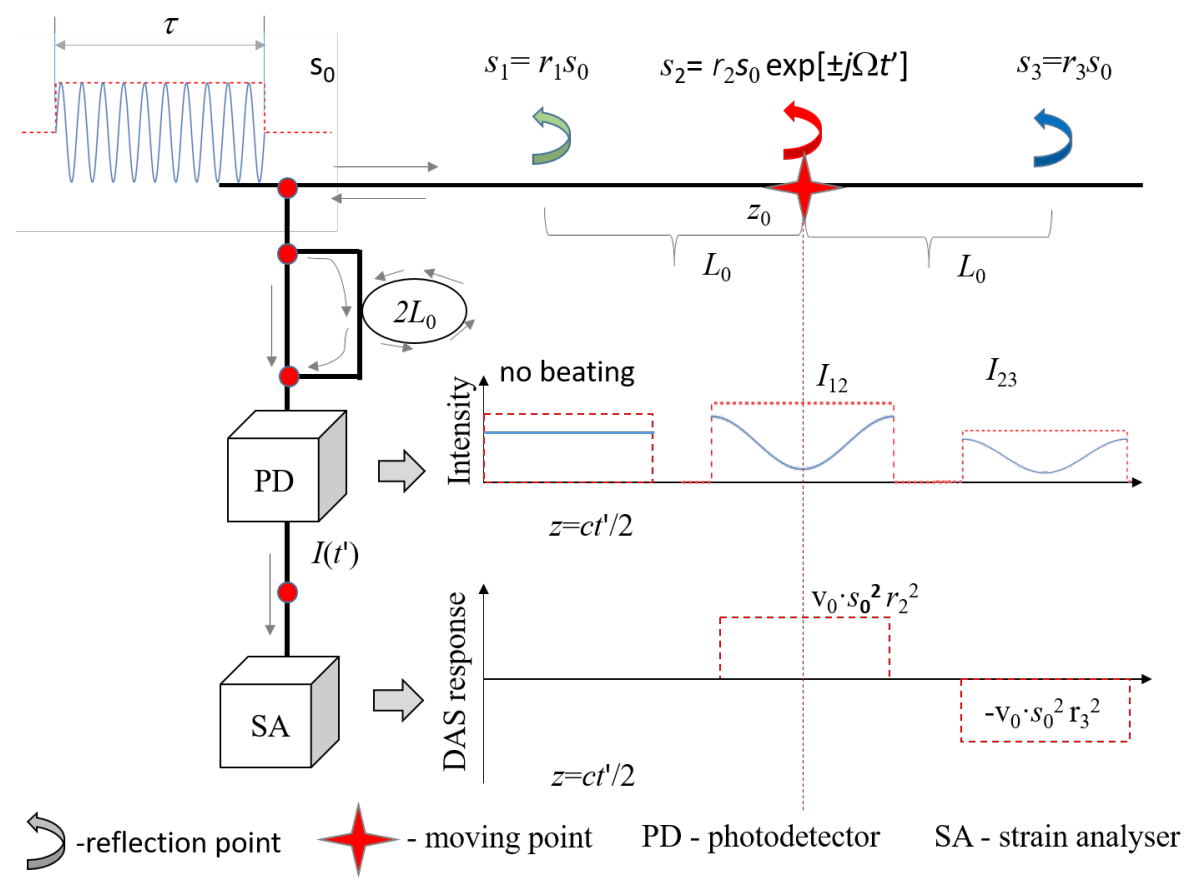

Figure A.8: A schematic illustration of the main principle behind the distributed acoustic measurements. A finite monochromatic laser pulse $s\left(t^{\prime}\right)$ reflects back continuously along the fibre, but at the moving point the reflected pulse $s_{2}$ also gains a time-dependent phase shift, which may be perceived as a Doppler frequency shift $\pm \Omega$ (the sign changes depending on whether $z<z_{0}$ or $z>z_{0}$ ). In a two-armed interferometer with a delay line of the length $2 L_{0}$, $s_{2}$ interferes first with a reflection $s_{1}$ passed through the delay line, and then $s_{2}$ passed through the delay line interferes with $s_{3}$ coming out of the straight line. For the both interferences, photon counts in the photodetector feature beating at the Doppler frequency $\Omega$. A strain analyser is a conceptual instrument that extracts the magnitude and sign of the beating of $\frac{\partial I(t)}{\partial t}$. 

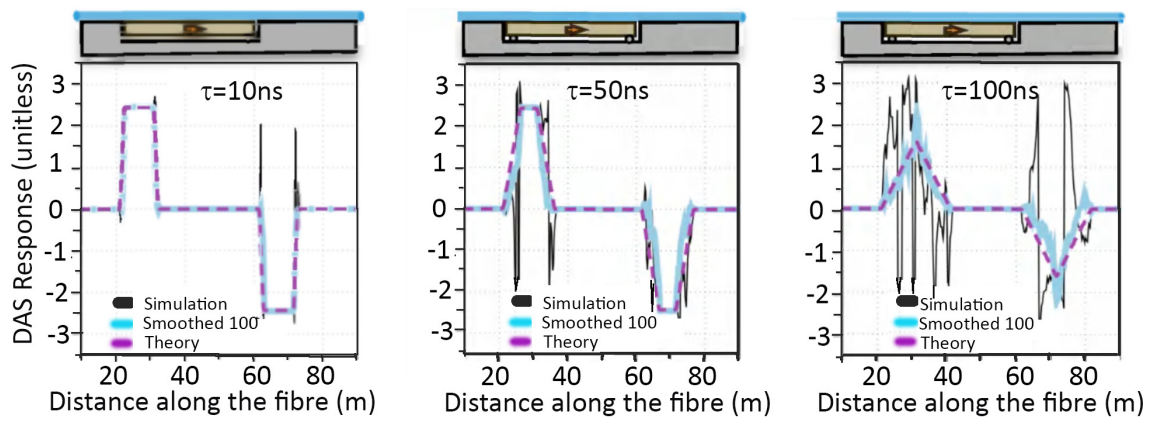

Figure A.9: Numerical simulations of the effect of fibre reflectivity fluctuations on a response of the distributed acoustic sensor corresponding to a laser pulse of duration 10ns (left), 50ns (middle) and 100ns (right). Simulated output (solid black line) features spikes due to the stochastic fluctuations of the fibre reflectivity. Averaging of 100 realisations of the reflectivity profile (solid cyan line) matches the theoretical prediction (dashed magenta line) according to eq. A.4. At the top of each plot we show schematically the location of a moving segment of the fibre.

On one hand, a longer pulse smooths out the instrumentation noise, but if a pulse is too long it becomes very sensitive to the inhomogeneities within the fibre. A compromise between the two considerations is usually achieved by choosing $L_{0}=2 \tau$. It is worth noting that the above simulation was carried out in the absence of noise. The fluctuations (fig. A.9 can be even more drastic when reflected light disappears for some distances. Such flicker noise can be suppressed partially by weighted averaging, but it is still a problem for DAS with a conventional fiber.

We can increase SNR and reduce the distortions simultaneously by using an engineered fiber with regularly spaced high reflectivity markers. With $L_{0}=2 \tau$, such a design prevents an overlap between the reflected pulses and minimises the effects of fluctuations of the fibre reflectivity. This idea is implemented in iDASv3 ${ }^{T M}$ system. The reflectivity of the engineered fibre becomes

$$
r(z)=R \cdot \sum_{j} \delta\left(z-j L_{0}\right)=R \cdot \operatorname{comb}(z / \tau)
$$

where $\operatorname{comb}(\cdot)$ is a comb function, also known as a sampling operator. DAS 
response for the engineered fiber $A_{E}(z)$ from eq. A.4 becomes

$$
A_{E}(z)=R^{2} \sum_{j}\left[v\left([j+1] L_{0}\right)-v\left(j L_{0}\right)\right] \tau^{2}\left(z-j L_{0}\right) .
$$

Then, the DAS output for the engineered fiber can be rearranged to a form similar to eq. A.6,

$$
A_{E}(z)=s_{0}^{2}(z) *\left\{\left[v(z)-v\left(z-L_{0}\right)\right] \operatorname{comb}(a / \tau)\right\}
$$

For the engineered fibre, effect of fluctuations of refraction index on the DAS response is negligible, and hence the ensemble averaging becomes unnecessary.

In Fourier domain with a spatial frequency $k_{z}$, the spectrum of the DAS response from eqs. A.7 and (A.8), $F_{E}\left(k_{z}\right)$, can be expressed via the spatial spectrum of the displacement velocity field along the fibre $F_{v}\left(k_{z}\right)$ as

$$
F_{E}\left(k_{z}\right)=F_{\mathrm{DAS}} \cdot\left[\operatorname{comb}\left(k_{z} \tau / 2 \pi\right) * F_{\mathrm{v}}\left(k_{z}\right)\right]
$$

where we assumed that the pulse is a unit rectangular function. The DAS receiver function $F_{\text {DAS }}$ is

$$
F_{\mathrm{DAS}}\left(k_{z}\right)=\omega \cdot\left|\operatorname{sinc}\left(k_{z} \tau / 2\right) \cdot \sin \left(k_{z} L_{0} / 2\right)\right|
$$

Because $v=\frac{\partial u(t)}{\partial t}$, conversion of the DAS measurements to displacements will feature also a factor $\omega$ (see 1).

We can conclude that, unlike DAS with a conventional fibre, the spectrum of the DAS response with an engineered fiber is subjected to aliasing similar to an array of geophones. Figure A.10 shows the spectra $F_{\text {DAS }}$ for typical parameters of DAS measurements. Clearly, an engineered fibre may be used until the cut-off frequency if an appropriate anti-aliasing filter is deployed, while a conventional fibre has no distortions in a wider frequency range, but its sensitivity drops with increasing frequency.

Design of the engineered fiber dictates the gauge length. However, it is possible to synthesise a long optical gauge length by shifting and stacking the measurements obtained with a short gauge length, as follows from eq. A.8. In 


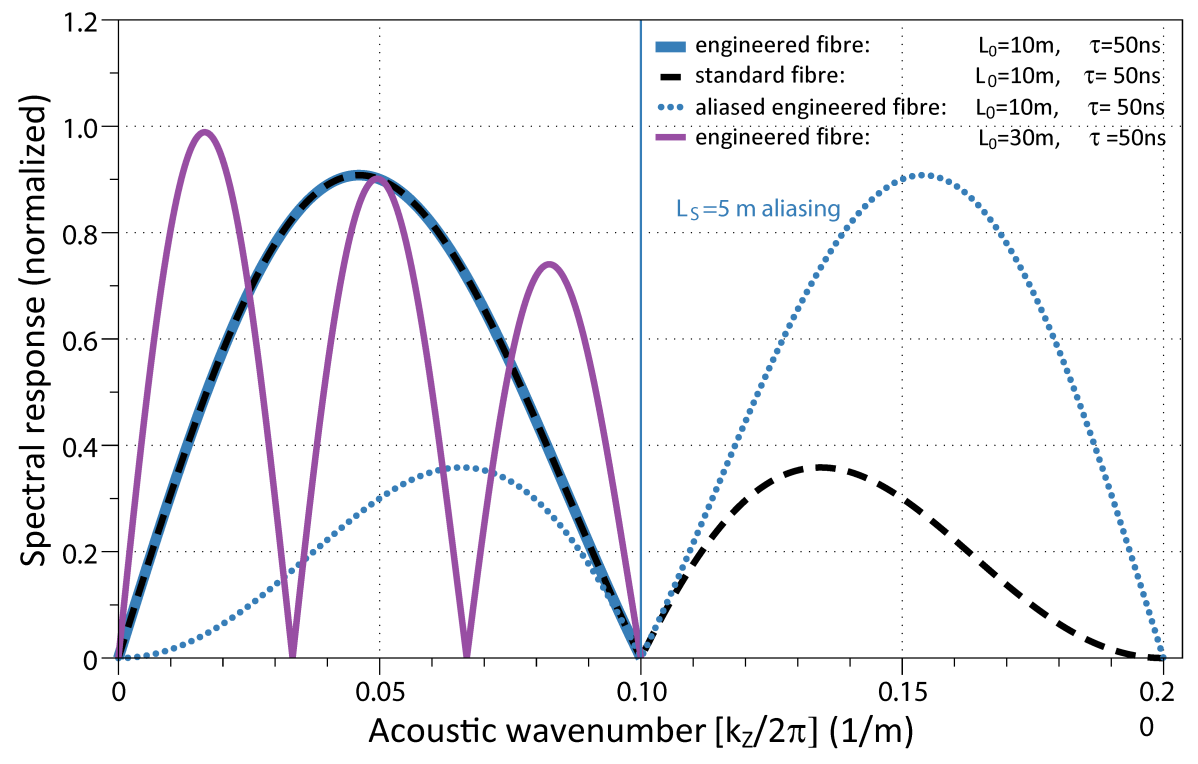

Figure A.10: Spatial spectrum of the response of distributed acoustic sensor (see eq. A.10) for various combination of the instrumentation parameters.

this case, the low-frequency response improves significantly, although the spatial bandwidth shrinks (see the line for long gauge length $L_{0}=30 \mathrm{~m}$ in fig. A.10.

\section{References}

Aki K, Richards P. Quantitative Seismology. University Science Books, 2002.

URL: https://books.google.com.au/books?id=sRhawFG5_EcC.

Ardhuin F, Lavanant T, Obrebski M, Marié L, Royer JY, d'Eu JF, Howe BM, Lukas R, Aucan J. A numerical model for ocean ultralow frequency noise: Wave-generated acoustic-gravity and rayleigh modes. The Journal of the Acoustical Society of America 2013;134(4):324259. URL: https://doi.org/10.1121/1.4818840 doi 10.1121/1.4818840

Aucan J, Fee D, Garcés M. Infrasonic estimation of surf period. Geophysical a Research Letters 2006;33(5). URL: https://agupubs.onlinelibrary. 
wiley.com/doi/abs/10.1029/2005GL025086. doi:10.1029/2005GL025086

arXiv:https://agupubs.onlinelibrary.wiley.com/doi/pdf/10.1029/2005GL025086

Brooks LA, Townend J, Gerstoft P, Bannister S, Carter L. Fundamental and higher-mode rayleigh wave characteristics of ambient seismic noise in new zealand. Geophysical Research Let-

a ters 2009;36(23). URL: https://agupubs.onlinelibrary.wiley. 555 com/doi/abs/10.1029/2009GL040434. doi:10.1029/2009GL040434, arXiv:https://agupubs.onlinelibrary.wiley.com/doi/pdf/10.1029/2009GL040434 
Collins CDN. Seismic velocities in the crust and upper mantle of Australia.

Technical Report 0084-7100 ; 277; Dept. of Primary Industries and Energy,

Bureau of Mineral Resources, Geology and Geophysics; 1988.

a

au/books?id=zptSBAAAQBAJ

Correa J, Egorov A, Tertyshnikov K, Bona A, Pevzner R, Dean T, Freifeld B, Marshall S. Analysis of signal to noise and directivity characteristics of DAS VSP at near and far offsets - A CO2CRC Otway Project data example. The Leading Edge 2017;36(12):994a1-7. URL: https: //doi.org/10.1190/tle36120994a1.1. doi 10.1190/tle36120994a1.1. arXiv:https://pubs.geoscienceworld.org/tle/article-pdf/36/12/994a1/3993258/tle36120994a1.1

Delaney E, Ermert L, Sager K, Kritski A, Bussat S, Ficht570 ner A. Passive seismic monitoring with nonstationary noise ¿ sources. GEOPHYSICS 2017;82(4):KS57-70. URL: https: //doi.org/10.1190/geo2016-0330.1 doi 10.1190/geo2016-0330.1 arXiv:https://doi.org/10.1190/geo2016-0330.1.

Dolgikh G, Chupin V, Gusev E. Microseisms of the "voice of the sea". IEEE 575 Geoscience and Remote Sensing Letters 2020;17(5):750-4.

Dorman J, Prentiss D. Particle amplitude profiles for rayleigh waves on a heterogeneous earth. Journal of Geophysical Research (1896-1977)

1 1960;65(11):3805-16. URL: https://agupubs.onlinelibrary.wiley. com/doi/abs/10.1029/JZ065i011p03805 doi 10.1029/JZ065i011p03805 arXiv:https://agupubs.onlinelibrary.wiley.com/doi/pdf/10.1029/JZ065i011p03805.

Egorov A, Correa J, Bóna A, Pevzner R, Tertyshnikov K, Glubokovskikh S, Puzyrev V, Gurevich B. Elastic full-waveform inversion of vertical seismic profile data acquired with distributed acousq tic sensors. GEOPHYSICS 2018;83(3):R273-81. URL: https: 
//doi.org/10.1190/geo2017-0718.1. doi:10.1190/geo2017-0718.1 arXiv:https://doi.org/10.1190/geo2017-0718.1.

Egorov A, Pevzner R, Bóna A, Glubokovskikh S, Puzyrev V, Tertyshnikov K, Gurevich B. Time-lapse full waveform inversion of vertical seismic profile data: Workflow and application to the CO2CRC Otway project. Geophysical Research Letters 2017;44(14):7211-8. URL: https : //agupubs . onlinelibrary . wiley.com/doi/abs/10.1002/2017GL074122, doi:10.1002/2017GL074122. arXiv:https://agupubs.onlinelibrary.wiley.com/doi/pdf/10.1002/2017GL074122

Ewing W, Jardetzky W, Press F. Elastic Waves in Layered Media. McGraw-Hill, 1957. URL: https://books.google.com.au/books?id=0B5RAAAAMAAJ.

595 Garcés M, Aucan J, Fee D, Caron P, Merrifield M, Gibson R, Bhattacharyya J, Shah S. Infrasound from large surf. Geophysical Re-

\ search Letters 2006;33(5). URL: https://agupubs.onlinelibrary. wiley.com/doi/abs/10.1029/2005GL025085. doi:10.1029/2005GL025085. arXiv:https://agupubs.onlinelibrary.wiley.com/doi/pdf/10.1029/2005GL025085.

${ }_{600}$ Gerstoft P, Sabra KG, Roux P, Kuperman WA, Fehler MC. Green's functions extraction and surface-wave tomography from microseisms in southern california. GEOPHYSICS 2006;71(4):SI23-31. URL: https://doi.org/10.1190/1.2210607 doi:10.1190/1.2210607 arXiv:https://doi.org/10.1190/1.2210607

Gimbert F, Tsai VC. Predicting short-period, wind-wave-generated seismic noise in coastal regions. Earth and Planetary Science Letters 2015;426:280

口-92. URL: http://wWw.sciencedirect.com/science/article/pii/ S0012821X15003738, doi/https://doi.org/10.1016/j.epsl.2015.06.017.

Glubokovskikh S, Pevzner R, Dance T, Caspari E, Popik D, Shu${ }_{610}$ lakova V, Gurevich B. Seismic monitoring of CO2 geosequestration: CO2CRC Otway case study using full 4D FDTD approach. Interna\ tional Journal of Greenhouse Gas Control 2016;49:201 -16. URL: http: 
//www.sciencedirect.com/science/article/pii/S1750583616300809.

doi:https://doi.org/10.1016/j.ijggc.2016.02.022.

1) URL: 10.1029/RG001i002p00177 arXiv:https://agupubs.onlinelibrary.wiley.com/doi/pdf/10.1029/RG001i002p00177

Haubrich RA, McCamy K. Microseisms: Coastal and

口 pelagic sources. Reviews of Geophysics 1969;7(3):53971

URL: https://agupubs.onlinelibrary.wiley.com/doi/ abs/10.1029/RG007i003p00539 doi 10.1029/RG007i003p00539 arXiv:https://agupubs.onlinelibrary.wiley.com/doi/pdf/10.1029/RG007i003p00539

Kibblewhite AC, Wu CY. The theoretical description of wave-wave interactions as a noise source in the ocean. The Journal of the Acoustical Society of America 1991;89(5):2241-52. URL: https://doi.org/10.1121/1.400970 doi:10.1121/1.400970 arXiv:https://doi.org/10.1121/1.400970.

Levchenko DG, Levchenko VD, Zakirov AV. Dynamic full-wave modeling of storm microseism propagation in an oceanic environment. Oceanol-

635 ogy 2011;51. URL: https://doi.org/10.1134/S0001437011040114, doi:10. 1134/S0001437011040114.

Lindsey NJ, Martin ER, Dreger DS, Freifeld B, Cole S, James SR, Biondi BL, Ajo-Franklin JB. Fiber-optic network observations of earthquake wavefields. Geophysical Research Letters 640 2017;44(23):11792-9. URL: https://agupubs.onlinelibrary.wiley. 


com/doi/abs/10.1002/2017GL075722. doi:10.1002/2017GL075722,
arXiv:https://agupubs.onlinelibrary.wiley.com/doi/pdf/10.1002/2017GL075722.
Lindsey NJ, Rademacher H, Ajo-Franklin JB. $\quad$ On the broad-
band instrument response of fiber-optic DAS arrays. Journal of
Geophysical Research: Solid Earth 2020;125(2):e2019JB018145.
URL:
abs/10.1029/2019JB018145.
arXiv:https://agupubs.onlinelibrary.wiley.com/doi/pdf/10.1029/2019JB018145;
e2019JB018145 10.1029/2019JB018145.

${ }_{650}$ Longuet-Higgins MS, Jeffreys H. A theory of the origin of microseisms. Philosophical Transactions of the Royal Society of London Series A, Mathematical and Physical Sciences

[ 1950;243(857):1-35. URL: https://royalsocietypublishing.org/ doi/abs/10.1098/rsta.1950.0012. doi:10.1098/rsta.1950.0012. arXiv:https://royalsocietypublishing.org/doi/pdf/10.1098/rsta.1950.0012.

McCreery CS, Duennebier FK, Sutton GH. Correlation of deep ocean noise $(0.4-30 \mathrm{~Hz})$ with wind, and the holu spectrum - a worldwide constant. The Journal of the Acoustical Society of America 1993;93(5):263948. URL: https://doi.org/10.1121/1.405838 doi:10.1121/1.405838 arXiv:https://doi.org/10.1121/1.405838.

Nakata N, Gualtieri L, Fichtner A. Seismic Ambient Noise. Cambridge University Press, 2019. doi:10.1017/9781108264808.

Pevzner R, Gurevich B, Pirogova A, Tertyshnikov K, Glubokovskikh S. Repeat well logging using earthquake wave amplitudes measured by distributed acoustic sensors. The Leading Edge 2020a;39(7):513-7. URL: https://doi.org/10.1190/tle39070513.1. doi:10.1190/tle39070513.1. arXiv:https://doi.org/10.1190/tle39070513.1.

Pevzner R, Tertyshnikov K, Sidenko E, Glubokovskikh S, Gurevich B. 
Trialling passive seismic with das in co2crc otway project: Ambi-

Pevzner R, Tertyshnikov K, Sidenko E, Yavuz S. Effects of cable deployment method on DAS vsp data quality: Study at CO2CRC Otway in-situ laboratory. In: 82nd EAGE Conference and Exhibition 2020, Extended Abstracts. Amsterdam: European Association of Gescientists \& Engineers; 2020c.

¿ URL: https://www . earthdoc.org/content/papers/10.3997/2214-4609. 202010765. doi https://doi.org/10.3997/2214-4609.202010765.

Pierson Jr. WJ, Moskowitz L. A proposed spectral form for fully developed wind seas based on the similarity theory of S. A. Kitaigorodskii. Journal of Geophysical Research (1896-1977) 1964;69(24):5181-

¿ 90. URL: https://agupubs.onlinelibrary.wiley.com/doi/ abs/10.1029/JZ069i024p05181. doi 10.1029/JZ069i024p05181. arXiv:https://agupubs.onlinelibrary.wiley.com/doi/pdf/10.1029/JZ069i024p05181.

Pirogova A, Pevzner R, Gurevich B, Glubokovskikh S, Tertyshnikov K. Multiwell study of seismic attenuation at the co2crc otway project geosequestration site: Comparison of amplitude decay, centroid frequency shift and 1d waveform inversion methods. Geophysical Prospect-

\ ing 2019;67(7):1778-97. URL: https://onlinelibrary.wiley.com/ doi/abs/10.1111/1365-2478.12796. doi:10.1111/1365-2478.12796. arXiv:https://onlinelibrary.wiley.com/doi/pdf/10.1111/1365-2478.12796.

Stephen RA, Spiess FN, Collins JA, Hildebrand JA, Orcutt JA, Peal KR, Vernon FL, Wooding FB. Ocean seismic network pilot experiment. Geochemistry, Geophysics, Geosys-

695 tems 2003;4(10). URL: https://agupubs.onlinelibrary.wiley. com/doi/abs/10.1029/2002GC000485. doi:10.1029/2002GC000485. arXiv:https://agupubs.onlinelibrary.wiley.com/doi/pdf/10.1029/2002GC000485 


Tanimoto T. $\quad$ Excitation of normal modes by non-linear in-
teraction of ocean waves.
$\begin{aligned} & \text { tional } 2007 ; 168(2): 571-82 . \\ & \text { 1365-246X.2006.03240.x. }\end{aligned}$
arXiv:https://academic.oup.com/gji/article-pdf/168/2/571/2015765/168-2-571.pdf.

Vaezi Y, van der Baan M. Analysis of instrument self-noise and microseismic event detection using power spectral density esti-

705 mates. Geophysical Journal International 2014;197(2):1076-89. URL: https://doi.org/10.1093/gji/ggu036. doi 10.1093/gji/ggu036 arXiv:https://academic.oup.com/gji/article-pdf/197/2/1076/1707949/ggu036.pdf.

Wapenaar K, Draganov D, Snieder R, Campman X, Verdel A. Tutorial on seismic interferometry: Part 1 - basic principles and applications. GEOPHYSICS 2010;75(5):75A195-20. URL: https://doi.org/10.1190/1.3457445 doi 10.1190/1.3457445 arXiv:https://doi.org/10.1190/1.3457445.

Webb SC. The equilibrium oceanic microseism spectrum. The Journal of the Acoustical Society of America 1992;92(4):2141-58. 715 URL: https://doi.org/10.1121/1.405226 doi:10.1121/1.405226 arXiv:https://doi.org/10.1121/1.405226.

Webb SC. Broadband seismology and noise under the ocean. Reviews of Geo¿ physics 1998;36(1):105-42. URL: https://agupubs.onlinelibrary.wiley. com/doi/abs/10.1029/97RG02287, doi:10.1029/97RG02287.

${ }_{720}$ Webb SC. The earth's 'hum' is driven by ocean waves over the continental shelves. Nature 2007;445. URL: https://doi.org/10.1038/nature05536 doi:10.1038/nature05536.

Welch P. The use of fast fourier transform for the estimation of power spectra: A method based on time averaging over short, modified periodograms. IEEE Transactions on Audio and Electroacoustics 1967;15(2):70-3. 
Williams EF, Fernández-Ruiz MR, Magalhaes R, Vanthillo R, Zhan Z, González-Herráez M, Martins HF. Distributed sensing of microseisms and teleseisms with submarine dark fibers. Nature Communications $2019 ; 5778(10): 1543-57 . \quad$ doi $10.1038 / \mathrm{s} 41467-019-13262-7$ arXiv:https://doi.org/10.1038/s41467-019-13262-7.

Ying Y, Bean CJ, Bromirski PD. Propagation of microseisms from the deep ocean to land. Geophysical Research Letters

1 2014;41(18):6374-9. URL: https://agupubs.onlinelibrary.wiley. com/doi/abs/10.1002/2014GL060979. doi:10.1002/2014GL060979 arXiv:https://agupubs.onlinelibrary.wiley.com/doi/pdf/10.1002/2014GL060979.

Yu C, Zhan Z, Lindsey NJ, Ajo-Franklin JB, Robertson M. The potential of DAS in teleseismic studies: Insights from the goldstone experiment. Geophysical Research Letters

n 2019;46(3):1320-8. URL: https://agupubs.onlinelibrary.wiley. com/doi/abs/10.1029/2018GL081195. doi:10.1029/2018GL081195. arXiv:https://agupubs.onlinelibrary.wiley.com/doi/pdf/10.1029/2018GL081195 